\title{
A Case of Antithyroid Drug-Induced Agranulocytosis Pre-Covid 19 Era
}

Sufian K. M. Noor ${ }^{1}$, Mosab Nouraldein Mohammed Hamad ${ }^{2}$, Sarra Osman Bushara ${ }^{1}$, Amel Abdalrhim Sulaiman ${ }^{3}$, Mohamed Adil Yassen $\mathrm{Ali}^{4}$, Remaz Khalid Hassan Ahmed ${ }^{4}$, Almotasim Mohamed Aabdelmgid Elnaema ${ }^{4}$, Samaher Mozamil Mohamed Abdelrahim ${ }^{4}$

${ }^{1}$ Medicine department, Faculty of Medicine, Nile Valley University, Atbara, Sudan

${ }^{2}$ Faculty of Health Sciences, Elsheikh Abdallah Elbadri University, Berber, Sudan

${ }^{3}$ Research and Information Unit, Public Health Department, Ministry of Health Saudi Arabia, Qassim Region, Saudi Arabia

${ }^{4}$ Medicine Department, Atbara Teaching Hospital, Atbara

Correspondence to: Mosab Nouraldein Mohammed Hamad, Faculty of Health Sciences, Elsheikh Abdallah Elbadri University, Berber, Sudan; E-mail: musab. noor13@gmail.com

Received date: November 08, 2020; Accepted date: November 17, 2020; Published date: November 25, 2020

Citation: Noor SKM, Mohammed Hamad MN, Bushara SO, et al. (2020) A Case of Antithyroid Drug-Induced Agranulocytosis Pre-Covid 19 Era. J Med Res Surg 1(6): pp. 1-3.

Copyright: (02020 Noor SKM, et al. This is an open-access article distributed under the terms of the Creative Commons Attribution License, which permits unrestricted use, distribution and reproduction in any medium, provided the original author and source are credited.

\section{ABSTRACT}

Agranulocytosis is an infrequent and serious side effect of antithyroid drugs characterized by a noticeable reduction in granulocyte and neutrophil count, it usually occurs within the first 2-3 months of treatment. There is a variety of mechanisms by which ATD can induce agranulocytosis, direct drug effects, and immunological mechanisms. We present 33 years old female attended Atbara teaching hospital who has developed agranulocytosis 2 weeks after starting ATD to treat relapsed Graves' disease. What was unusual about this patient is that symptoms have occurred in a period less than 15 days of starting treatment and with a dose of $45 \mathrm{mg} /$ day. The physician must educate the patient about the possibility of early onset of serious side effects of ATD and to seek medical advice as soon as possible.

\section{Keywords:}

Agranulocytosis, Neomercazole, Hyperthyroidism, Graves' disease

\section{Abbreviations}

ATD: Antithyroid Drug; CZ: Carbimazole; MZ: Methimazole; TWBC: Total White Blood Count; PTU: Propylthiouracil; ANC: Absolute Neutrophil Count.

\section{Introduction}

Basedow's (Graves') sickness is an autoimmune disease characterized by hyperthyroidism due to circulating autoantibodies. Thyroid immunoglobulin bind to active thyrotropin receptors causing the thyroid gland to grow and thyroid follicle to increase the synthesis of thyroid hormone [1]. According to the American thyroid association radioactive iodine, thyroidectomy and antithyroid drugs are the standard management for Graves' disease [2] Carbimazole is a prodrug which is converted into Methimazole (the active form), it's used for the treatment of hyperthyroidism totaling a dose of $30-60 \mathrm{mg} /$ day, but the maximum dose should be $120 \mathrm{mg} /$ day [3] MZ and CZ are associated with an adverse side effect, one of them Agranulocytosis which is rare but can be fatal [4]. Agranulocytosis is characterized by a marked reduction in granulocyte and neutrophil count, it usually occurs within the first 2-3 months of treatment [5].

\section{Clinical Case}

33 years old female patient attended to Atbara teaching hospital who is a known case of Graves' disease underwent subtotal thyroidectomy 14 years ago she has been on thyroxin $50 \mathrm{mg}$ once daily she remained euthyroid all that time till the last month when she developed palpitation, weight loss despite increase appetite, sweating, menstrual irregularity, and irritability. thyroid function test showed (TSH $0.02 \mu \mathrm{lU} / \mathrm{ml}$, free T3 $5.6 \mathrm{ng} / \mathrm{ml}$, T4 $2.1 \mathrm{ug} / \mathrm{ml}$ ) patient was diagnosed as relapsed graves' disease and received Neomercazole $15 \mathrm{mg}$ three times a day and B blocker for symptoms control, then 15 days after initiation of ATD patient has developed a severe sore throat and high-grade fever, she sought medical advice at local ENT center. On physical examination, there was tonsillitis and pharyngitis and lab result revealed low TWBCs $1.3 \times 10^{3} / \mu \mathrm{l}$, based on drug history of ATD use, physical examination, and lab result the otolaryngologist referred the patient to our clinic stating his concern about the seriousness of the patient condition. After the patient's arrival to our clinic, On evaluation patient reported 3 days of sore throat and high-grade fever, she reported no travel history, sick contact or taking other medication. Physical examination revealed high-grade fever "39 C", bilateral enlargement of submandibular lymph node and tachycardia, thyroid gland examination not tender, no hotness, mildly enlarged.

Blood test demonstrated low TWBC $1.3 \times 10^{3} / \mu$ l count and absolute neutrophil count was 0 cell/ul and CRP was 106. Urine general was normal. Based on history, examination and lab result $C Z$ induced Agranulocytosis was strongly suspected. Accordingly, CZ was immediately stopped and broad-spectrum antibiotics were prescribed. On the follow up 3 days later her symptoms improved, CBC showed that TWBCs $3.8 \times 10^{3} / \mu \mathrm{I}$ ANC returned to the normal "1.9" lab reference "1.4-6.5" Accordingly she was discharged home and planned for radioactive iodine as definitive treatment. 


\section{Discussion}

$\mathrm{CZ}$ and $\mathrm{MZ}$ have widely used medications for the treatment of graves disease. They act by inhibiting thyroperoxidase enzyme which is essential in thyroid hormone synthesis $C Z$ and $M Z$ both have the same mechanism of action, they are considered identical [4]. Propylthiouracil was used for a long time until the US Food and Drug Administration (FDA) added a warning that there is an increased risk of severe liver injury and acute liver failure, and it may be fatal so it is only reserved for patients who can't tolerate other treatment options such as $M Z$ or surgery [6] there are several adverse effects associated with $\mathrm{MZ}$ and $\mathrm{CZ}$ ranging from mild (pruritus and urticaria) to severe (Agranulocytosis and Steven-Johnson syndrome) [4].

There are a variety of mechanisms by which ATD can induce Agranulocytosis: it may be due to the direct toxic effect of the drug when ATD penetrates the bone marrow; through there, oxide metabolites affect oxygen and glucose utilization of the leukocytes leading to their destruction [7]. However other studies contradict the hypothesis of the direct effect of the drug on leukocytes they suppose that carbimazole-induced agranulocytosis is found to be occurring through a drug mediated reaction rather than the direct toxic effect of the drug [8].

Wall et al. study reported that in vitro peripheral lymphocyte transformation and circulating Antibodies against neutrophils have been detected in a patient with ATD induced agranulocytosis [9].

The immune-mediated destruction of mature neutrophils was the first mechanism to be identified as a cause of ATD induced Agranulocytosis [10]. Sprikkelman et al. described different four immunological mechanisms that can be responsible [10]. Firstly, the destruction of granulocyte due to antibodies formed against ATD and bound to the granulocyte membrane leading to an acceleration of granulocyte destruction. Secondly, the target of the antibodies may be the drug -metabolites complex that has been absorbed into the neutrophil granulocyte in the presence of the plasma component. Thirdly, Autoantibodies may be triggered by the drug, and finally, the production of antibodies may be induced by the interaction between the drug and the granulocyte antigen.

Also, other immunological reactions may occur like induced hypersensitivity reaction mediated by IgE, drug-induced IgG and IgM responses, and associated immune injury by antineutrophil cytoplasm antibodies ANCA which may contribute to Agranulocytosis [11-13].

The relationship between the dose of ATD and the incidence of Agranulocytosis is debatable and age-related. a study made by Yasuda et al on pediatric patients with Graves' disease found that the incidence of a variety of adverse events occurs more often in patients who are on a high dose of methimazole $(0.7$ or more $\mathrm{mg} / \mathrm{kg} /$ day) than those on a low dose $(<0.7 \mathrm{mg} / \mathrm{kg} /$ day) with frequencies of adverse events being $50 \%$ and $20 \%$ respectively. However, neutropenia was found to manifest independently of dose [14]. As we can see from our case agranulocytosis has occurred with a low dose of ATD $15 \mathrm{mg}$ per day. On the other hand, Cooper et al study concluded that methimazole doses greater than $30 \mathrm{mg} /$ day and or age $>40$, are associated with a higher risk of development of agranulocytosis
[15]. Leukopenia in patients with hyperthyroidism may be caused by thyrotoxicosis itself or may be related to ATD [16]. ANC rarely fall below $\left.2000 \times 10^{6}\right) /$, this is neither associated with an increase in the risk of infection nor necessitate drug discontinuation [17-18].

The majority of ATD induced Agranulocytosis usually occur within 2 months of treatment [15-19]. the clinical presentation is usually infection in the oropharyngeal region, fever and sore throat are the most common presenting symptoms [20-21] our case presented with typical manifestations of ATD induced agranulocytosis; sore throat and fever.

In our case, it occurred within the first 2 weeks of treatment. Usually, it takes two weeks after stopping the offending drug for leukocyte count to return to normal [22]. However, The restoration of TWBCs from $1.3 \times 10^{3} / \mu \mathrm{l}$ to $3.8 \times 10^{3} / \mu \mathrm{l}$ and Absolute neutrophil count was rapid and dramatic in our case it took only 3 days after discontinuation of the ATD, even without administration of Granulocyte colony-stimulating factor, however, there case report in Taiwan Ming-Tsung et al. [23] the recovery time of TWBCs took only 3 days.

\section{Conclusion}

Agranulocytosis is a rare serious side effect of ATD, that can occur at any dose and as early as 15 days, in our case, it is clear that the patient wasn't vigilant about the onset of serious side effect of her prescribed drugs; we have noticed that she went to the ENT clinic considering her symptoms as symptoms of ordinary throat infection. That could lead to delay of appropriate treatment and raise the risk of the onset of serious complications like sepsis, peritonsillar abscess, or retropharyngeal and consequent upper airway obstruction. Fortunately, she is referred to her original physician early and appropriate management was done. Finally, what we have learned from this case is that when the physician prescribes ATD for a patient he/she should warn the patient in written or verbal meanings that he or she should seek physician advice and obtain blood analysis as soon as he or she feels sore throat or common cold symptoms.

\section{References}

1. Jim Yeung SC, (2020) Graves' Disease https://emedicine.medscape.com/article/120619-overview

2. Ross DS, Burch HB, Cooper DS, et al. (2016) 2016 American Thyroid Association guideline for diagnosis and management of hyperthyroidism and other causes of thyrotoxicosis. Thyroid 26(10): pp. 1343-1421.

3. Dipiro JT, Talbert RL, Yee GC, et al. Pharmacotherapy: $A$ pathophysiological Approach pp. 131026.

4. Kim H, Lee J, Ha J, et al. (2018) A case of antithyroid druginduced agranulocytosis from a second Antithyroid Drugs (ATD) administration in a relapsed Graves' disease patient who was tolerant to the first ATD treatment. Clin Case Rep 6(9): pp. 1701-1703.

5. Tajiri J, Noguchi S (2004) Antithyroid drug induced agranulocytosis: special reference to normal white blood cell count agranulocytosis. Thyroid 14(6): pp. 459-62.

6. Mohlin E, Nystrom HF, Eliasson M (2014) Long-term prognosis after medical treatment of Graves disease in a northern 
Swedish population 2000-2010. Eur J Endocrinol 170(3): pp. 419-27.

7. Waldhauser L, Uetrecht J (1991) Oxidation of propylthiouracil to reactive metabolites by activated neutrophils. Implications for agranulocytosis. Drug Metab Dispos 19(2): pp. 354-9.

8. Cooper DS (2005) Antithyroid drugs. N Engl J Med 352(9): pp. 905-917.

9. Wall JR, Fang SL, Kuroki T, et al. (1984) In vitro immunoreactivity to propylethiouracil, methimazol, and carbimazole in patient with Graves' disease: a possible cause of antithyroid druginduced agranulocytosis. J Clin Endocrinol Metab 58(5): pp. 868-72.

10. Spikkelman A, de Wolf JT and Vellenga E (1994) The application of hematopoietic growth factors in drug-induced agranulocytosis: a review of 70 Cases. Leukemia 8(12): pp. 2031-6.

11. Sun MT, Tsai CH, Shih KC (2009) Antithyroid drug induced agranulocytosis. J Chin Med Assoc 72(8): pp. 438-441

12. Akamizu T, Ozaki S, Hiratani H, et al (2002) Drug-induced neutropenia associated with anti-neutrophil cytoplasmic antibodies (ANCA): possible involvement of compliment in granulocyte cytotoxicity. Clin Exp Immunol. 127(1): pp. 92-98.

13. Harper L, Chin L, Daykin J, et al. (2004) Propylthiouracil and carbimazole associated- antineutrophil cytoplasmic antibodies (ANCA) in patient with Graves' disease. Clin Endocrinol (Oxf) 60(6): pp. 671-5.

14. Yasuda K, Miyoshi Y, Tachibana M, et al. (2017) Relationship between dose of antithyroid drugs and adverse event in paediatric patients with Graves' disease. Clin Pediatr Endocrinol
26(1): pp. 1-7.

15. Cooper DS, Goldminz D, Levin AA, et al. (1983) Agranulocytosis Associated with antithyroid drugs. Effects of patient age and drug dose. Ann Intern Med 98(1): pp. 26-9.

16. Larsen PR, Davies TF, Hay ID (1998) The thyroid gland. In: Wilson JD; Foster DW, Kronenberg HM, Larsen PR, eds. Williams Textbook of Endocrinology, 9th edition Philadelphia, WB Saunders;389-515.

17. Cooper DS (1984) Antithyroid drugs. N Engl J Med 311(21): pp. 1353-62.

18. Werner MC, Romaodini JH, Bromberg N, et al. (1984) Adverse effects related to thionomide drug and their dose regimen. AM J Med Sci 297(4): pp. 216-219.

19. Cooper DS, (2005) Antithyroid drugs. N Engl J Med 352: pp 905-917.

20. Astwood EB , Bissel A, hughes AM (1945) Further studies on the chemical nature of compounds which inhibit the thyroid gland. Endocrinol 37(6): pp. 456-481.

21. Emiliano AB, Governale L, Parks M, et al. (2010) Shifts in propylthiouracil and Methimazole prescribing Practices: Antithyroid drug use in the United states from 1991 to 2008. J Clin Endocrinol Metab 95(5): pp. 2227-2233.

22. Gessner MM, Benker G, Lederbogen S, et al. (1994) Antithyroid drug-induced agranulocytosis. Clinical experience with ten patients treat at one institution and review of literature . J Endocrinol Invest 17(1): pp. 29-36.

23. Sun MT, Tsai CH, Shih KC, (2009) Antithyroid Drug-induced Agranulocytosis, Journal of the Chinese Medical Association 72(8): pp. $438-41$ 